\title{
Are rich nations up for drug reform?
}

The global debate over the high cost of drugs reaches Geneva this month, when the governing body of the World Health Organization (WHO) will consider two proposals aimed at reshaping the forces that drive medical research and development.

The proposals direct the WHO to act on two controversial issues: the lack of affordable, effective medicines for people in poor countries, and the international intellectual-property system that governs the distribution of medical treatments.

Developed countries especially the United States have in the past strongly opposed such interventions, perceiving them as a threat to the drug industry. But this is the first time the issues have been addressed by the WHO, and advocates for reform are optimistic. Many believe that recent trends - such as the massive and growing cost of health care in the United States, the scarcity of treatments for avian influenza, and the lack of biodefence countermeasures against diseases such as anthrax - are persuading the

Western world that the current system does not meet all public-health needs.

The first proposal to come before the World Health Assembly, the WHO's governing body, is raised by Kenya and Brazil, and calls on the agency to consider measures that would boost the development of new drugs. The reform movement stems from a growing concern about the lack of treatments, vaccines and diagnostic products for diseases that affect developing countries. For instance, one study found that only $1 \%$ of drugs brought to market between 1975 and 1999 targeted tuberculosis and tropical diseases such as malaria

"An increasing percentage of new drugs are slight variations of alreadyapproved medications."

(P. Trouiller et al. Lancet 359, 2188-2194; 2002). The other 99\% targeted disorders more relevant to the developed world, such as cancer and heart disease.

But the lack of new treatments is now affecting richer countries too. Other studies have found, for example, that an increasing percentage of new drugs are slight variations of alreadyapproved medications. "There's possibly a recognition that something's going to have to change," says Tim Hubbard, a genome biologist at the Wellcome Trust Sanger Institute in Cambridge, UK, who has become heavily involved in the issue. "Everyone can see that spending on research and development is going up, but the number of new drugs coming to market is going down."

The proposal has been endorsed by a long list of consumer groups, activists and scientists, including Hubbard. It doesn't endorse specific reforms, although advocates have suggested many options, from an international fund for research into neglected diseases, to a cash prize for developers of innovative drugs.

The important thing, they say, is that the WHO commits to tackling the issue. "It's been an uphill struggle to get the WHO interested in this question, and if you look at the enormous health needs out there you think, how the hell can this be the case?" says Ellen 't Hoen of Genevabased Médecins Sans Frontières.

The second proposal asks the WHO to act on the issue of whether patent laws restrict access to essential medicines. It follows a report commissioned by the WHO, released on 3 April, which concluded that the patent system is not working to drive innovation in drugs needed by poor countries. It makes 50 recommendations for action.

The proposals will be heard when the assembly meets on 22-27 May. Advocates are encouraged that rich nations have not yet taken up a strong position against them. Erika Check

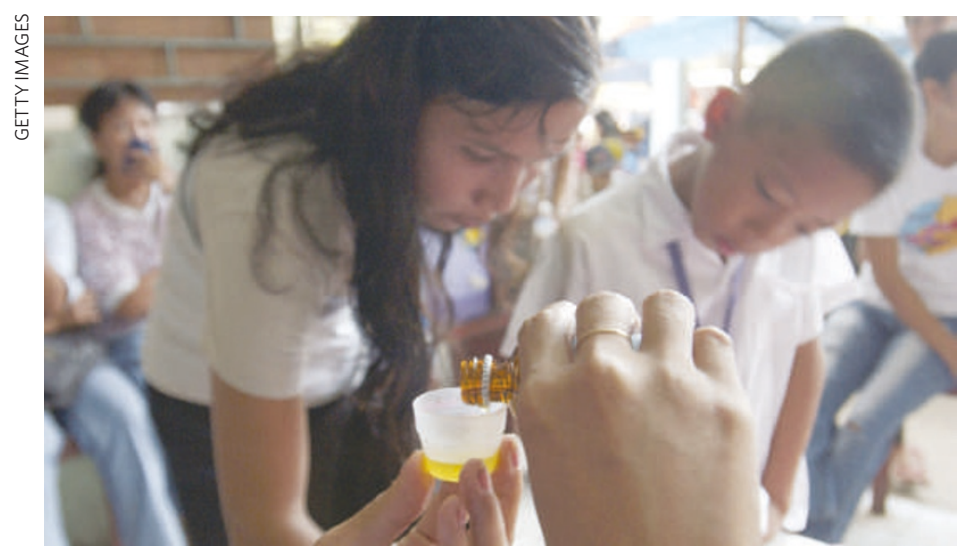

There is growing concern about the lack of treatments and vaccines for diseases that affect developing countries. 